\title{
Tumor-sealing Surgical Orthotopic Implantation of Human Colon Cancer in Nude Mice Induces Clinically-relevant Metastases Without Early Peritoneal Carcinomatosis
}

\author{
SANG NAM YOON ${ }^{1,2,3}$, JUN HO PARK ${ }^{1,2,4}$, THINZAR M. LWIN $^{1,2}$, KENTARO MIYAKE $^{1,2,5}$, \\ SHREE RAM SINGH ${ }^{6}$, ROBERT M. HOFFMAN ${ }^{1,2,7}$ and MICHAEL BOUVET ${ }^{2,7,8}$ \\ ${ }^{1}$ AntiCancer, Inc., San Diego, CA, U.S.A.; \\ ${ }^{2}$ Department of Surgery, University of California, San Diego, CA, U.S.A.; \\ ${ }^{3}$ Department of Surgery, Kangnam Sacred Heart Hospital, \\ Hallym University College of Medicine, Seoul, Republic of Korea; \\ ${ }^{4}$ Department of Surgery, Kangdong Sacred Heart Hospital, \\ Hallym University College of Medicine, Seoul, Republic of Korea; \\ ${ }^{5}$ Department of Gastroenterological Surgery, Yokohama City University \\ Graduate School of Medicine, Yokohama, Japan; \\ ${ }^{6}$ Basic Research Laboratory, National Cancer Institute, Frederick, MD, U.S.A.; \\ ${ }^{7}$ Veterans Affairs San Diego Healthcare System, San Diego, CA, U.S.A.; \\ ${ }^{8}$ Moores Cancer Center, University of California San Diego, San Diego, CA, U.S.A.
}

\begin{abstract}
Background: Surgical orthotopic implantation of human colon cancer tissue to the ceca of mice has been used to mimic behavior of cancer in human patients for the development of precision cancer medicine. However, with the current method of serosal surface implantation (SSI) of pieces of human colon cancer tissue, cancer cells are exposed to the peritoneum, which can artificially increase the rate of peritoneal carcinomatosis $(P C)$ during the disease course. The objective of the present study was to introduce a tumorsealing method (TSM) and compare it with SSI for the ability to produce clinically-relevant metastases without artificial PC. Materials and Methods: HCT116 colon cancer cells transfected with green fluorescence protein (GFP) were cultured and then injected into the subcutaneous layer of
\end{abstract}

Correspondence to: Michael Bouvet, MD, Department of Surgery, University of California San Diego Moores Cancer Center, 3855 Health Sciences Drive, \#0987, La Jolla, CA 92093-0987 U.S.A. Tel: +1 8588226191, e-mail: mbouvet@ucsd.edu; Shree Ram Singh, Ph.D., Basic Research Laboratory, National Cancer Institute, Frederick, MD 21702, U.S.A. Tel: +1 3018467331, e-mail: singhshr@mail.nih.gov; Robert M. Hoffman, Ph.D., AntiCancer, Inc., 7917 Ostrow Street, San Diego, CA 92111, U.S.A. Tel: +1 8586542555, Fax: +1 8582684175, e-mail: all@anticancer.com

Key Words: Orthotopic xenograft, HCT116, colon cancer, surgical orthotopic implantation, cecum, microsurgery, mouse model, metastasis, peritoneal carcinomatosis, survival. athymic nude mice. Subcutaneous tumors were allowed to grow sufficiently to supply adequate tumor for orthotopic implantation. For SSI, a $1 \mathrm{~mm}^{3}$-sized tumor fragment was sutured to partially torn serosa of the cecum. For TSM, the blind end of the cecum was folded over the tumor fragment and sealed with sutures. At 20 days after implantation, all mice were opened to visualize PC by intravital fluorescence imaging. At necropsy, distant metastasis was investigated using frozen section of whole blocks of organs. Results: At 20 days after implantation, $P C$ rates in the SSI group and the TSM group were $80 \%$ (12/15) and $20 \%$ (3/15), respectively $(p<0.001)$. The liver metastasis rate was $41.7 \%(5 / 12)$ in the SSI group and 50\% (5/10) in the TSM group ( $p=0.696)$. The lung metastasis rate was $0 \%(0 / 12)$ in the SSI group and $10 \%$ (1/10) in the TSM group $(p=0.201)$. The mean survival of mice without PC on the 20th day was significantly longer than that of mice with PC on the 20th day (69.1 $\pm 14.7 \mathrm{vs.}$ 44.5 \pm 12.4 days, $p=0.001)$. Conclusion: These results suggest that TSM might be a more patient-like and useful method as a model of metastatic colon cancer than SSI.

Colorectal cancer is the third most common cancer and the third leading cause of cancer death in men and women in the United States (1). The mortality resulting from this disease, much as many other solid tumors, is not from the primary tumor itself but from metastasis (2). Numerous in vitro studies have been performed to study processes of cancer cell motility, invasion, and growth. However, these studies 
look at steps of metastasis in isolation using monolayer cell culture that lacks the complexity associated with the process in an in vivo setting (3). Three-dimensional histoculture is a useful alternative to monolayer culture because it preserves the native architecture of cells (4). However, it is still an in vitro setting that does not allow the study of metastasis. Thus, there is a need to develop animal models for human cancer which can only occur in an animal model.

Tumors implanted into the subcutaneous layer of athymic nude mice can provide information about tumor growth. However, metastatic rates from subcutaneous tumors have been low or nonexistent, even from tumors that were highly metastatic in the patient from whom the tissue was derived (5). In 1982, Sordat et al. developed the concept of orthotopic xenografts, in which human cancer cells were implanted in nude mice into the corresponding organ from which cancer cells were derived in humans, resulting in cancer-cell invasion which was not observed in subcutaneously-implanted tumors (6). However, orthotopic implantation of cancer cell suspensions surprisingly resulted in a low metastatic frequency (7).

Our laboratory pioneered implantation of fragments of tumor surgically (surgical orthotopic implantation, SOI) to the serosal surface of the bowel, which resulted in a high level of metastasis (7-10). Disaggregated cancer cells, obtained by disrupting the original structure of human tumor tissue, may lead to a change in the nature and biological behavior of the tumor and reduce the frequency of metastasis (4, 10). A much greater extent of metastasis has been observed after SOI compared to orthotopic implantation of cell suspension (for example, in stomach cancer) (10).

To date, serosal surface implantation (SSI) has been used for SOI, with tumor fragments implanted on the surface of the cecal serosa with minimal serosal tear. However, SSI exposes the tumor to the peritoneal space, which might artificially cause peritoneal carcinomatosis. In fact, extensive peritoneal carcinomatosis has been observed in use of SSI (8).

In the present study, we modified SOI by folding the cecum and sealing the tumor in order to prevent peritoneal exposure to fragments of tumor after implantation. This new method is termed the tumor-sealing method (TSM) of SOI. In the present study, HCT116 human colon cancer cells, transfected with green fluorescence protein (GFP), were used to compare SSI and TSM SOI methods for metastatic outcomes and survival in nude-mouse models.

\section{Materials and Methods}

Cell culture. The HCT116 human colon cancer cell line has been well characterized in many studies and found to grow rapidly in nude mice (11-16). Thus, it was chosen for the present study. This cell line originated from a 48-year-old male who underwent an operation for ascending colon carcinoma at Dukes' D stage. Characteristics of this tumor included microsatellite instability, positivity for $\mathrm{CpG}$ island methylator phenotype panels 1 and 2, chromosomal instability pathway- negative, KRAS proto-oncogene, GTPase (KRAS $\left.{ }^{\mathrm{G} 13 \mathrm{D}}\right)$, wild-type B-Raf proto-oncogene, serine/ threonine kinase $(B R A F)$, phosphatidylinositol-4,5-bisphosphate 3kinase catalytic subunit alpha $(P I K 3 C A)^{\mathrm{H} 1047 \mathrm{R}}$ wild-type phosphatase and tensin homolog $(P T E N)$, and wild-type tumor protein 53 (TP53) (11). This cell line was originally obtained from the American Type Culture Collection (Manassas, VA, USA). These cells were maintained in RPMI 1640 supplemented with $10 \%$ fetal bovine serum and $1 \% 2 \mathrm{mmol} / 1$ glutamine (Life Technologies, Inc., Grand Island, NY, USA) at $37^{\circ} \mathrm{C}$ in an incubator with $5 \% \mathrm{CO}_{2}$.

GFP transfection. HCT116 cells were transfected with GFP for more accurate detection by fluorescence imaging. Packaging cells 293 GP (Clontech, Mountain View, CA, USA) were co-transfected with a plasmid encoding vesicular stomatitis virus glycoprotein envelope protein and a retroviral vector encoding GFP and G418 resistance gene using FuGene (Invitrogen, Carlsbad, CA, USA). Viruses were collected 48 hours later. They were used to infect HCT116 cells. After 48 hours, infected HCT116 cells were selected by treatment with G418 for 5 days, resulting in stable expression of $\operatorname{GFP}(12,15)$.

Animal care. Athymic nu/nu nude mice (AntiCancer Inc., San Diego, CA, USA) 5 to 6 weeks old were used in this study. These mice were bred and maintained in a high-efficiency particulate air-filtered environment at AntiCancer, Inc. with cages, food, and bedding sterilized by autoclave. Animal diets were obtained from Harlan Teklad (Madison, WI, USA). Ampicillin (5.0\%, w/v; Sigma, St. Louis, MO, USA) was added to autoclaved drinking water. All surgical procedures and intravital imaging were performed with animals anesthetized by intramuscular injection of $0.02 \mathrm{ml}$ of a mixture of $50 \%$ ketamine, $38 \%$ xylazine, and $12 \%$ acepromazine maleate. All animal studies were conducted under assurance number A3873-1 issued to AntiCancer, Inc. and the principles and procedures outlined in the National Institutes of Health (NIH) Guide for the Care and Use of Animals (17).

Subcutaneous tumor implantation. HCT116 GFP-labeled cells $\left(5 \times 10^{6}\right)$ were harvested from in vitro culture by trypsinization and washed twice with serum-free medium. These cells were injected into the subcutaneous layer on the right flank of nude mice within $30 \mathrm{~min}$ after harvesting. Subcutaneous tumors were allowed to grow for 2-4 weeks until large enough to supply adequate tumor size (about $1 \mathrm{~cm}$ ) for orthotopic implantation.

Orthotopic tumor implantation. The subcutaneous tumor was resected aseptically, and necrotic tissues were cut away. Remaining healthy tumor tissues were then scissor-minced into fragments of about 1-mm in diameter in RPMI media. In the SSI group $(8,9,12,18-20)$ (Figure 1A), the cecum was delivered through a small 6 to $10-\mathrm{mm}$ left paramedian vertical abdominal incision and a small segment of bowel and mesentery were exposed. Tumor fragments were fixed to the mesenteric border of the cecal wall using 8-0 nylon surgical sutures. The serosa of the site where the tumor fragment was to be implanted was partially torn in advance. In the TSM group (Figure 1B), after fixing the tumor fragment, the cecum was folded to cover the tumor fragment and the periphery was sutured with 8-0 nylon. A new set of surgical instruments was used after completing the SSI procedure to avoid cancer-cell contamination around the folded area. Upon completion, the cecum was returned to the abdomen and the wound was closed in two layers using 6.0 Ethibond non-absorbable sutures (Ethicon Inc., Somerville, NJ, USA). 
Table I. Comparison between serosal surface implantation (SSI) and the tumor-sealing method (TSM) for surgical orthotopic implantation (SOI) of colon cancer in a nude mouse model.

\begin{tabular}{llccc}
\hline Timing & & SSI $(\mathrm{n}=15)$ & TSM $(\mathrm{n}=15)$ & $p$-Value \\
\hline \multirow{2}{*}{ Day 20 } & Tumor volume $\left(\mathrm{mm}^{3}\right)$ & $258.1 \pm 227.0$ & $262.3 \pm 211.7$ & $3(20)$ \\
& PC $(\%)$ & $12(80)$ & $12 / 3 / 0 / 0(80 / 20 / 0 / 0)$ & 0.960 \\
& PC grade 0/I/II/III (\%) & $3 / 7 / 2 / 3(20 / 46.7 / 13.3 / 20)$ & $56.5 \pm 14.5$ & 0.002 \\
Necropsy & Necropsy day & $53.0 \pm 20.9$ & $1618.1 \pm 1507.4$ & 0.661 \\
& Tumor volume $\left(\mathrm{mm}^{3}\right)$ & $1289.9 \pm 631.0$ & $8 / 10(80)$ & 0.537 \\
& PC, (\%) & $10 / 12(83.3)$ & $5 / 10(50)$ & 0.840 \\
& Liver metastasis (\%) & $5 / 12(41.7)$ & $1 / 10(10)$ & 0.201 \\
\hline
\end{tabular}

Peritoneal Carcinomatosis (PC) grade: 0: No seeding nodules; 1: 1-15 seeding nodules; 2: 16-99 seeding nodules; 3: $>100$ seeding nodules.

Imaging to detect primary tumor growth, metastasis, and peritoneal carcinomatosis in vivo. In vivo images were acquired for all mice through a laparotomy to detect the presence or absence of peritoneal carcinomatosis, as well as primary tumor growth and metastasis, on the 20th day after orthotopic implantation (Figure 2). The mean survival time of mice carrying HCT116 cells has been reported to be 39 days [16]. Thus, we chose day 20 as half of the mean survival time. All abdominal organs were explored along the midline incision as described above. Two imaging devices were used to obtain fluorescence images: an OV100 Small Animal Imaging System (Olympus Corp., Tokyo, Japan) containing an MT-20 light source (Olympus Biosystems, Planegg, Germany) with a DP70 CCD camera (Olympus Corp.) (21), and an iBox Small Animal Imaging System (UVP, Upland, CA, USA) equipped with a BioChemi HR500 CCD camera (UVP) and a BioLite automated multispectral light source (UVP) (18-22).

PC was graded based on the number of peritoneal seeding nodules: Grade 0 , no seeding nodule was found; grade I, 1 to 15 nodules; grade II, 16 to 100 nodules; and grade III, more than 100 nodules. Tumor volume was estimated as (long diameter $\times$ short diameter $\left.{ }^{2}\right) / 2$.

Imaging to visualize distant metastases at necropsy. At animal death, a complete necropsy procedure was performed. Thoracic and abdominal organs were extracted. The presence of local tumor at the cecum was assessed, its long and short diameters measured, and all macroscopic and microscopic tumor deposits in the liver, lung, lymph nodes, and peritoneal carcinomatosis were recorded. Each organ, including primary tumors, livers, lungs, lymph nodes, and peritoneal seeding nodules of necropsied mice, was excised. Tissues were embedded in tissue-freezing medium (Triangle Biomedical Science, Durham, NC, USA), frozen in liquid nitrogen for $10 \mathrm{~min}$, and placed at $-80^{\circ} \mathrm{C}$ overnight. These tissue samples were then frozen in TissueTek O.C.T. compound (Sakura Fintek, Torrance, CA, USA) and sectioned on a microtome. Frozen sections at $15-\mu \mathrm{m}$ in thickness were prepared with a Leica CM1850 cryostat (23) for fluorescence microscopy. These sections were air-dried for 5-10 min and imaged with a confocal microscope (Fluoview FV1000; Olympus Corp.). A continuous-wave semiconductor laser at $473 \mathrm{~nm}$ for GFP excitation and a tunable Mai Tai HP femtosecond laser emitting at 700-1,020 $\mathrm{nm}$ (Newport-Spectra Physics, Irvine, CA, USA) were used for deep tissue imaging of GFP. Fluorescence images were obtained using Olympus $4 \times / 0.13$ and $20 \times / 0.50$ UPLFLN objectives (24).
Statistical analysis. Pearson's chi-square tests were used for categorical variables (PC, liver metastasis, and lung metastasis) and independent sample $t$-tests were used for continuous variables (tumor volume). Kaplan-Meier with the log-rank test was used for survival analysis. A two-tailed value of $p<0.05$ was considered statistically significant. All calculations were performed using SPSS version 24.0 (IBM SPSS Statistics, IBM Corporation, Armonk, NY, USA).

\section{Results}

The PC rate was $80 \%(12 / 15)$ in the SSI group and $20 \%$ $(3 / 15)$ in the TSM group $(p=0.001)$ on the 20th day after SOI (Table I). The PC grade was also higher in the SSI group than that in the TSM group $(p=0.002)$. Estimated mean primary tumor volume was similar in both groups. Representative images of PC grade 0 to III are shown in Figure 2.

Primary tumor take rates observed at necropsy were $80 \%$ $(12 / 15)$ in the SSI group and $66.7 \%(10 / 15)$ in the TSM group. At necropsy, more than $80 \%$ mice showed PC in both groups. The liver metastasis rate was $41.7 \%(5 / 12)$ in the SSI group and $50 \%(5 / 10)$ in the TSM group $(p=0.696)$. The lung metastasis rate was $0 \%(0 / 12)$ in the SSI group and $10 \%$ $(1 / 10)$ in the TSM group $(p=0.201)$. Representative images of liver and lung metastases are shown in Figure 3.

Survival rates were similar between the SSI group and the TSM group (Figure 4A). However, the mean survival of mice without PC on the 20th day was significantly longer than that of mice with PC on the 20th day $(69.1 \pm 14.7$ days vs. 44.5 \pm 12.4 days, $p=0.001$ ) (Figure 4B).

\section{Discussion}

The present study used the HCT116 cell line tagged with GFP so that we could easily detect PC and distant metastases with fluorescence imaging. The present study is the first to seal the tumor fragment by folding the cecum for SOI in a mouse model of colon cancer to prevent early PC.

We wished to find a better way to make a more physiological SOI model. Our results showed that the rate 

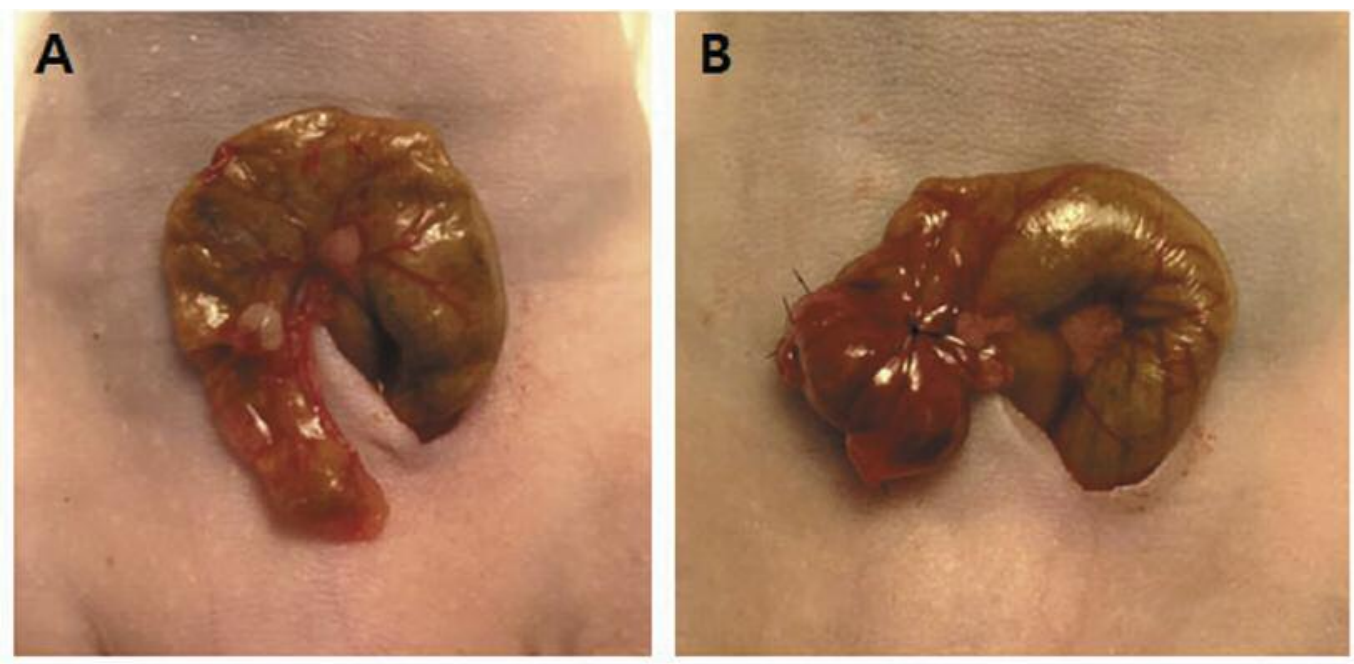

Figure 1. A: Serosal surface implantation - a tumor fragment was fixed on the partially torn serosal surface of the cecum. B Tumor-sealing method - after tumor fragment fixation, the cecum was folded to cover the fragment and the periphery was sealed with sutures.
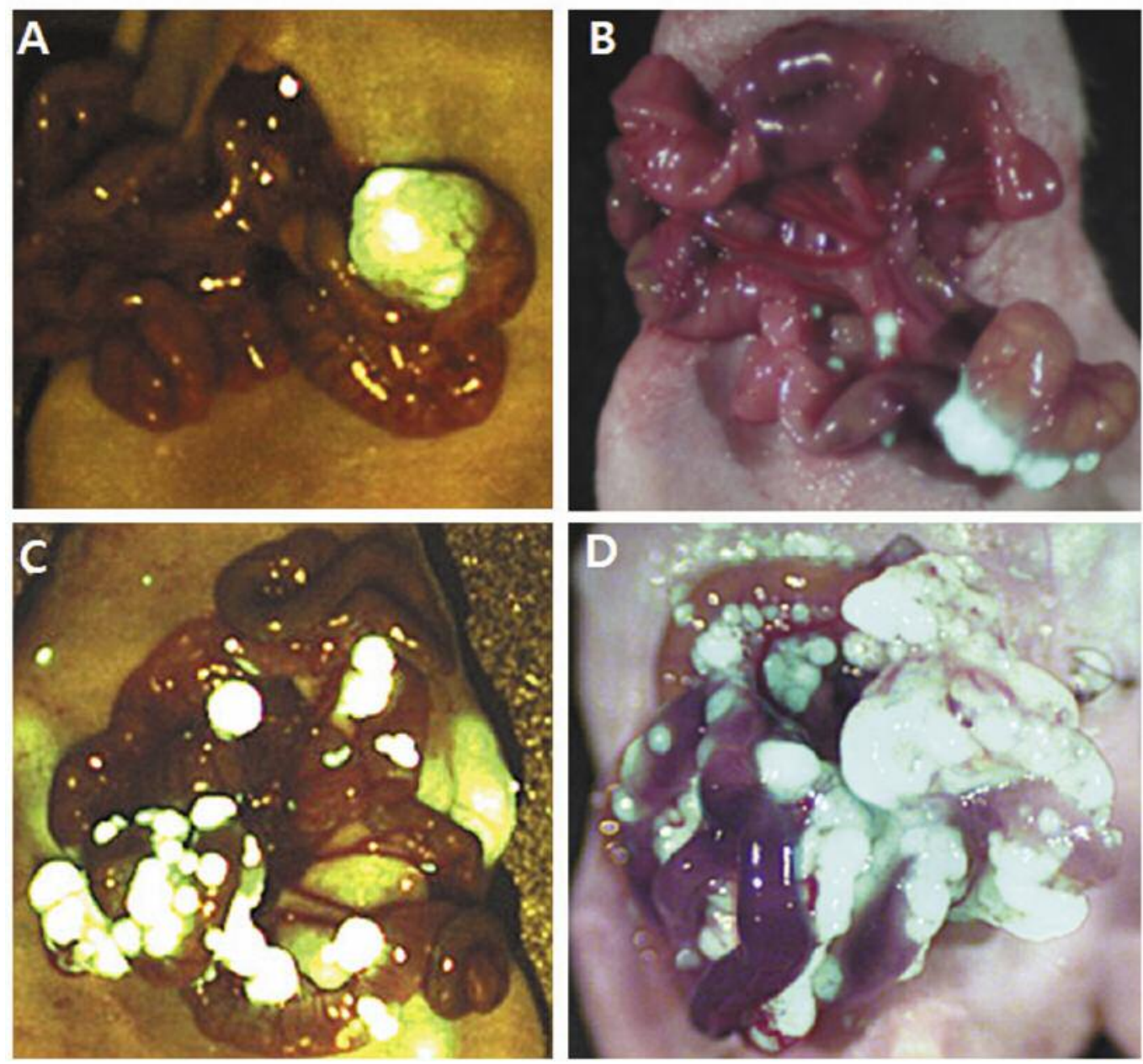

Figure 2. Representative images of peritoneal carcinomatosis of grade $O(A), I(B), I I(C)$ and III (D) on day 20. 

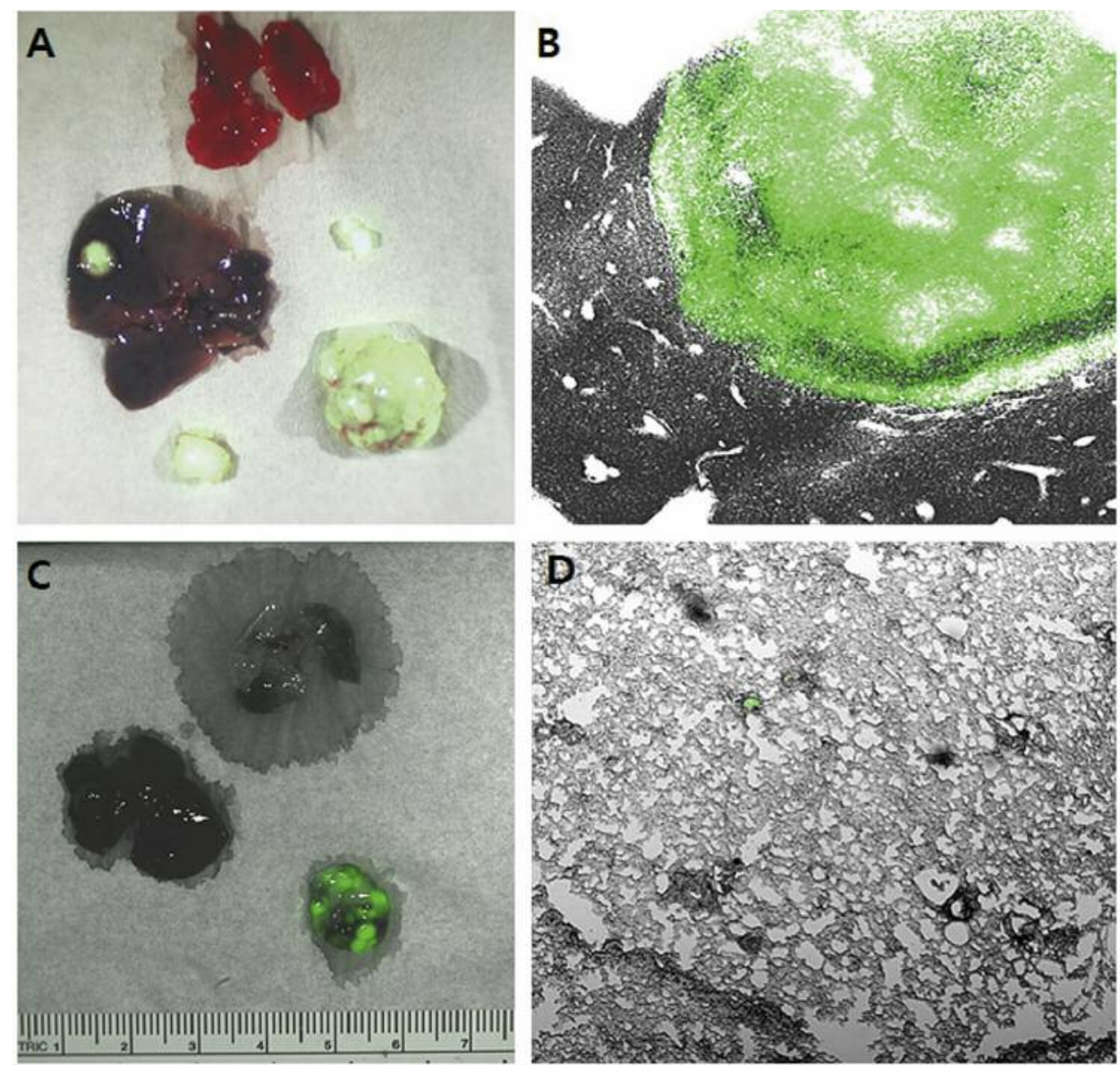

Figure 3. Representative images showing distant metastases. A: Liver metastasis (gross). B: Liver metastasis (x4). C: Lung metastasis (gross). D: Lung metastasis $(\times 4)$.

A

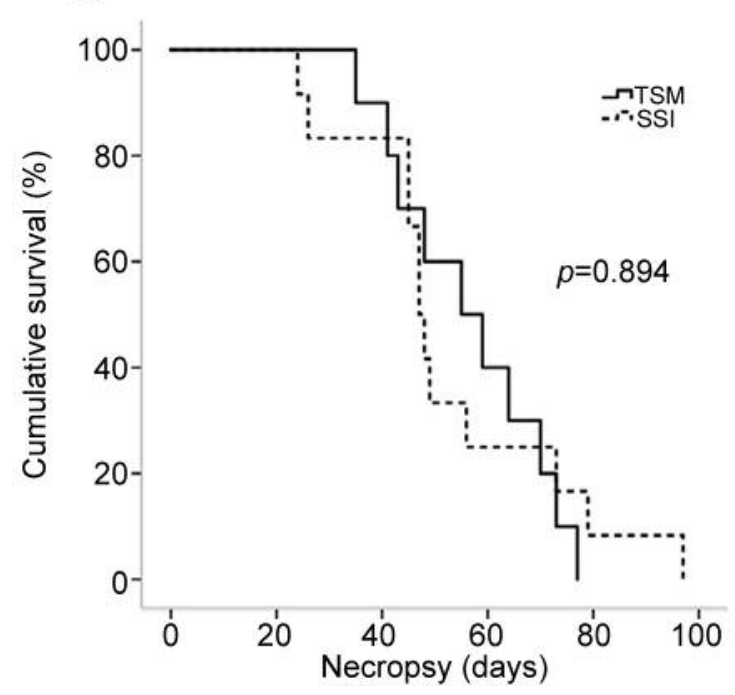

B

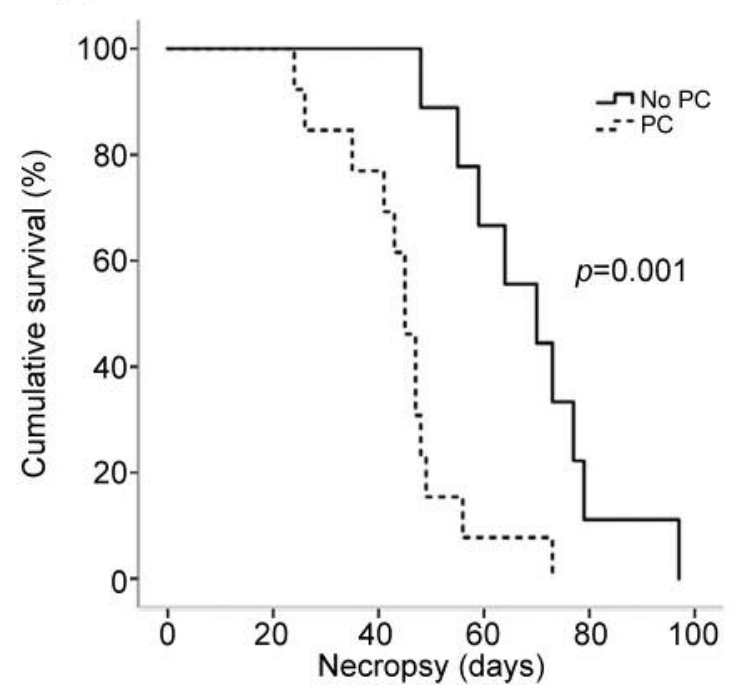

Figure 4. Survival curves for mice according to the method used to produce the model (A) and presence or not of peritoneal carcinomatosis (PC) (B). TSM: Tumor-sealing method; SSI: serosal surface implantation. 
of PC on the 20th day was much lower in the TSM group than in the SSI group. The survival rate of mice that showed high PC on the 20th day was significantly lower. On the other hand, both methods resulted in a similar pattern of distant metastasis. Rates of liver metastasis in the present study were similar to those of previous reports $(16,24)$. Lung metastasis was only detected in one case of the TSM group. Previous studies reported various rate of lung metastasis $(16,18,24)$. We believe PC that develops early in mice might alter the disease course and shorten their survival. We expect TSM-SOI will be more clinically relevant in that it prevents $\mathrm{PC}$ at an early state and it showed a pattern of distant metastasis similar to that with SSI.

In conclusion, the TSM group had a lower rate of early PC than did the SSI group. Both groups showed a similar pattern of distant metastasis at necropsy. Mice without early PC survived longer. Thus, TSM might be used as a better mouse model of metastatic colon cancer than the currently used (25).

\section{Ethical Approval}

The study was carried out under an AntiCancer Institutional Animal Care and Use Committee-approved protocol.

\section{Authors Contributions}

SNY conceived and carried out the experiments with the collaboration of JHP, TML, and KM. SNY wrote the first draft. $\mathrm{RMH}, \mathrm{SRS}$, and MB reviewed and revised the article.

\section{Conflicts of Interest}

SNY, JHP, KM, and RMH are or were unsalaried associates of AntiCancer Inc. AntiCancer Inc. uses orthotopic mouse model for contract research. The Authors have no conflicts of interest relevant to this study to disclose.

\section{References}

1 Siegel R, Desantis C and Jemal A: Colorectal cancer statistics, 2014. CA Cancer J Clin 64: 104-117, 2014. PMID: 24639052. DOI: $10.3322 /$ caac. 21220

2 Rodrigues RV, Pereira da Silva J, Rosa I, Santos I, Pereira N, Soares $\mathrm{C}$ and Pereira AD: Intensive follow-up after curative surgery for colorectal cancer. Acta Med Port 30: 633-641, 2017. PMID: 29025530. DOI: 10.20344/amp.7889

3 Hölzel F, Albrecht M, Simon WE, Hänsel M, Metz R, Schweizer $\mathrm{J}$ and Dietel M: Effectiveness of antineoplastic drugs on the proliferation of human mammary and ovarian carcinoma cells in monolayer culture. J Cancer Res Clin Oncol 109: 217-26, 1985. PMID: 4008518.

4 Hoffman RM: Three-dimensional histoculture: Origins and applications in cancer research. Cancer Cells 3: 86-92, 1991. PMID: 2054260.
5 Kyriazis AP, Yagoda A, Kyriazis AA and Royer GL Jr.: Experimental studies on the response of nude mouse-grown human urothelial cancer to high dose of 1-beta-D-arabinofuranosylcytosine. Cancer Invest 6: 145-149, 1988. PMID: 3378191.

6 Sordat BCM, Ueyama Y and Fogh J: Metastasis of tumor xenografts in the nude mouse. In: The Nude Mouse in Experimental and Clinical Research. 2. Fogh J and Giovanella BC (eds.). New York: Academic Press, p. 95-147, 1982.

7 Hoffman RM: Patient derived orthotopic xenografts: Better mimic of metastasis than subcutaneous xenografts. Nature Rev Cancer 15(8): 451-452, 2015. PMID: 26422835. DOI: $10.1038 / \mathrm{nrc} 3972$

8 Fu XY, Besterman JM, Monosov A and Hoffman RM: Models of human metastatic colon cancer in nude mice orthotopically constructed by using histologically intact patient specimens. Proc Natl Acad Sci USA 88: 9345-9349, 1991. PMID: 1924398.

9 Fu X, Herrera H, Kubota T and Hoffman RM: Extensive liver metastasis from human colon cancer in nude and scid mice after orthotopic onplantation of histologically-intact human colon carcinoma tissue. Anticancer Res 12: 1395-1397, 1992. PMID: 1444196.

10 Furukawa T, Fu X, Kubota T, Watanabe M, Kitajima M and Hoffman RM: Nude mouse metastatic models of human stomach cancer constructed using orthotopic implantation of histologically intact tissue. Cancer Res 53: 1204-1208, 1993. PMID: 8439965.

11 Ahmed D, Eide PW, Eilertsen IA, Danielsen SA, Eknæs M, Hektoen M, Lind GE and Lothe RA: Epigenetic and genetic features of 24 colon cancer cell lines. Oncogenesis 2: e71, 2013. PMID: 24042735. DOI: 10.1038/oncsis.2013.35

12 Rajput A, Dominguez San Martin I, Rose R, Beko A, Levea C, Sharratt E, Mazurchuk R, Hoffman RM, Brattain MG and Wang $\mathrm{J}$ : Characterization of HCT116 human colon cancer cells in an orthotopic model. J Surg Res 147: 276-281, 2008. PMID: 17961596. DOI:10.1016/j.jss.2007.04.021

13 Brattain MG, Fine WD, Khaled FM, Thompson J and Brattain DE: Heterogeneity of malignant cells from a human colonic carcinoma. Cancer Res 41: 1751-1756, 1981. PMID: 7214343.

14 Bresalier RS, Raper SE, Hujanen ES and Kim YS: A new animal model for human colon cancer metastasis. Int J Cancer 39: 62530, 1987. PMID: 3032811

15 Bouvet M, Tsuji K, Yang M, Jiang P, Moossa AR and Hoffman RM: In vivo color-coded imaging of the interaction of colon cancer cells and splenocytes in the formation of liver metastases. Cancer Res 66: 11293-11297, 2006. PMID: 17145875. DOI: 10.1158/0008-5472.CAN-06-2662

16 Céspedes MV, Espina C, García-Cabezas MA, Trias M, Boluda A, Gómez del Pulgar MT, Sancho FJ, Nistal M, Lacal JC and Mangues R: Orthotopic microinjection of human colon cancer cells in nude mice induces tumor foci in all clinically relevant metastatic sites. Am J Pathol 170: 1077-1085, 2007. PMID: 17322390. DOI: 10.2353/ajpath.2007.060773

17 Higuchi T, Kawaguchi K, Miyake K, Han Q, Tan Y, Oshiro H, Sugisawa N, Zhang Z, Razmjooei S, Yamamoto N, Hayashi K, Kimura H, Miwa S, Igarashi K, Chawla SP, Singh AS, Eilber FC, Singh SR, Tsuchiya H and Hoffman RM: Oral recombinant methioninase combined with caffeine and doxorubicin induced regression of a doxorubicin-resistant synovial sarcoma in a PDOX mouse model. Anticancer Res 38(10): 5639-5644, 2018. PMID: 30275182. DOI: 10.21873/anticanres.12899 
18 Hoffman RM and Yang M: Whole-body imaging with fluorescent proteins. Nature protoc 1(3): 1429-1438, 2006. PMID: 17406431. DOI: $10.1038 /$ NProt.2006.223

19 Rashidi B, Sun FX, Jiang P, An Z, Gamagami R, Moossa AR and Hoffman RM: A nude mouse model of massive liver and lymph node metastasis of human colon cancer. Anticancer Res 20: 715-722, 2000. PMID: 10810345.

20 Hiroshima Y, Maawy A, Metildi CA, Zhang Y, Uehara F, Miwa S, Yano S, Sato S, Murakami T, Momiyama M, Chishima T, Tanaka K, Bouvet M, Endo I and Hoffman RM: Successful fluorescence-guided surgery on human colon cancer patientderived orthotopic xenograft mouse models using a fluorophoreconjugated anti-CEA antibody and a portable imaging system. J Laparoendosc Adv Surg Tech A 24(4): 41-247, 2014. PMID: 24494971. DOI: 10.1089/lap.2013.0418

21 Yamauchi K, Yang M, Jiang P, Xu M, Yamamoto N, Tsuchiya $\mathrm{H}$, Tomita K, Moossa AR, Bouvet $\mathrm{M}$ and Hoffman RM: Development of real-time subcellular dynamic multicolor imaging of cancer-cell trafficking in live mice with a variablemagnification whole-mouse imaging system. Cancer Res 66 : 4208-4214, 2006. PMID: 16618743. DOI: 10.1158/00085472.CAN-05-3927

22 Tran Cao HS, Kimura H, Kaushal S, Snyder CS, Reynoso J, Hoffman RM and Bouvet M: The cyan fluorescent protein (CFP) transgenic mouse as a model for imaging pancreatic exocrine cells. J Pancreas 10: 152-156, 2009. PMID: 19287108.

23 Uchugonova A, Duong J, Zhang N, Konig K and Hoffman RM: The bulge area is the origin of nestin-expressing pluripotent stem cells of the hair follicle. J Cell Biochem 112: 2046-50, 2011. PMID: 21465525. DOI: $10.1002 /$ jcb .23122
24 Puig I, Chicote I, Tenbaum SP, Arqués O, Herance JR, Gispert JD, Jimenez J, Landolfi S, Caci K, Allende H, Mendizabal L, Moreno D, Charco R, Espín E, Prat A, Elez ME, Argilés G, Vivancos A, Tabernero J, Rojas $\mathrm{S}$ and Palmer HG: A personalized preclinical model to evaluate the metastatic potential of patient-derived colon cancer initiating cells. Clin Cancer Res 19: 6787-6801, 2013. PMID: 24170545. DOI: 10.1158/1078-0432.CCR-12-1740

25 Julien S, Merino-Trigo A, Lacroix L, Pocard M, Goéré D, Mariani P, Landron S, Bigot L, Nemati F, Dartigues P, Weiswald LB, Lantuas D, Morgand L, Pham E, Gonin P, Dangles-Marie V, Job B, Dessen P, Bruno A, Pierré A, De Thé H, Soliman H, Nunes M, Lardier G, Calvet L, Demers B, Prévost G, Vrignaud P, RomanRoman S, Duchamp O and Berthet C: Characterization of a large panel of patient-derived tumor xenografts representing the clinical heterogeneity of human colorectal cancer. Clin Cancer Res 18: 5314-5328, 2012. PMID: 22825584. DOI: 10.1158/10780432.CCR-12-0372
Received June 1, 2019

Revised June 29, 2019

Accepted July 3, 2019 